\title{
Long term serological surveillance after treatment of Helicobacter pylori infection
}

Department of Gastroenterology, Leiden University Hospital R A Veenendaal A S Peña

J L Meijer

M M C van der Est

W van Duijn

$\mathrm{J}$ Kreuning

C B H W Lamers

Department of

Pathology, Leiden

University Hospital

F Eulderink

Department of Medical Microbiology, Leiden

University Hospital

$\mathrm{H}$ Ph Endtz

Correspondence to:

$R$ A Veenendaal, Department

of Gastroenterology, Leiden

of Gastroenterology, Leiden

1, C4, P14, PO Box 7600, 2300

RC Leiden, The Netherlands.

Accepted for publication

28 January 1991

\author{
R A Veenendaal, A S Peña, J L Meijer, H Ph Endtz, M M C van der Est, W van Duijn, \\ F Eulderink, J Kreuning, C B H W Lamers
}

\begin{abstract}
Fifteen patients with type B gastritis caused by Helicobacter pylori infection were treated with 'triple' therapy consisting of colloidal bismuth subcitrate, amoxycillin, and metronidazole. All were followed up as outpatients every three months for at least one year. After 'triple' therapy a significant $(p<0.01)$ and persistent reduction in IgA and IgG antibody levels against $H$ pylori was detected. In three patients recurrent active infection with $H$ pylori at nine and 12 months was detected by a rise in IgA (three patients) and IgG (two patients) antibody levels against $H$ pylori and worsening of symptoms, and was confirmed by culture and histology. In 11 patients, the absence of infection at 12 months was confirmed by culture and histology. In a control group of 13 patients with type B gastritis who received no antibacterial treatment, specific IgA and IgG antibody levels against $H$ pylori remained unchanged during 12 months of follow up. Although specific IgG against $H$ pylori is the most widely used serological test for screening, our data indicate that specific IgA is also valuable in monitoring treatment. These serological tests are easy to perform, relatively inexpensive, devoid of radioactivity and are very acceptable to patients. It is concluded that serological testing is the preferred method for follow up after treatment for $\boldsymbol{H}$ pylori infection and will probably replace endoscopy or the urea breath test.
\end{abstract}

Helicobacter pylori is a curved spiral Gram negative bacterium that lives in the human stomach. Since the first description of $H$ pylori, ${ }^{1}$ it has been established as the cause of type B gastritis ${ }^{23}$ and as an important pathogenic factor in duodenal ulcer disease. ${ }^{45}$ Recently, eradication of $H$ pylori infection has been proposed as the new mainstay of duodenal ulcer treatment.

There are several sensitive and specific tests available for the diagnosis of $H$ pylori. The presence of the bacterium in gastric biopsy specimens can be detected directly by culture ${ }^{6}$ and histology ${ }^{78}$ or indirectly by using the strong urease $^{9}$ produced by the bacterium. For screening and follow up after treatment non-invasive tests are preferable. Urea breath tests are reliable and non-invasive but require an expensive mass spectrometer or produce radioactive waste with a long half-life. ${ }^{1011}$

The presence of specific IgA and IgG antibodies against $H$ pylori can be shown by the relatively inexpensive and generally available technique of enzyme linked immunosorbent assay (ELISA). ${ }^{12-14}$ We followed two groups of patients - treated and untreated for $H$ pylori infection - to see whether monitoring of treatment by means of serology was informative with regard to eradication of $H$ pylori.

\section{Patients and methods}

Fifteen patients, whose mean age was 52 years, and male to female ratio (M:F) $1 \cdot 5$, with dyspeptic symptoms, positive $H$ pylori culture, and histological evidence of type $B$ gastritis, were treated with triple therapy consisting of bismuth subcitrate $120 \mathrm{mg}$ qds for 28 days, amoxycillin $500 \mathrm{mg}$ qds, and metronidazole $500 \mathrm{mg}$ qds for 10 days. All patients had raised serum antibodies against $H$ pylori determined by ELISA.

The patients have been followed as outpatients, initially at six weeks and then every three months for at least one year. Thirteen patients (mean age 61 years, M:F 5.5) with $H$ pylori positive gastritis who received no antibacterial treatment were also followed by means of serology every three months for a year. This group, with high antibody values confirming $H$ pylori infection, served as control group. In this non-randomised study controls were selected whose antibody values matched those of the patients receiving treatment and who shared the same ethnic background.

Patients who took antibiotics or bismuthcontaining drugs before the study or during follow up were excluded. The controls received maintenance treatment with $\mathrm{H}_{2}$ antagonists.

At the three monthly visits, symptoms were recorded and blood was taken for serological tests. Endoscopy (Olympus, GIF K10) was performed before treatment, and at three and 12 months afterwards. Additional endoscopies were performed if there was no improvement in symptoms, when symptoms recurred, or when there was an appreciable rise in antibody values. Each patient underwent an average of $4 \cdot 2$ endoscopies. Follow up was stopped when infection with $H$ pylori was diagnosed. Controls underwent an endoscopy at 12 months of follow up.

At upper gastrointestinal endoscopy, biopsy specimens were taken from the antrum with a sterilised biopsy forceps, $2 \mathrm{~cm}$ proximal to the pylorus in intact mucosa. One specimen was transported to the laboratory in $0.2 \mathrm{ml}$ sterile $0.9 \% \mathrm{NaCl}$ and inoculated by rubbing onto the surface of a blood agar plate (Blood Agar Base No 2, Oxoid CM 271, containing 5\% sheep blood) and onto Skirrow's medium. The cultures were incubated at $37^{\circ} \mathrm{C}$ in a nitrogen atmosphere containing $8 \% \mathrm{CO}_{2}$ and $6 \% \mathrm{O}_{2}$ for five days. The bacteria were identified as $H$ pylori on the basis of their morphology, oxidase, catalase, and urease production. Another specimen was immediately 
Figure 1: Development of specific IgA anti-H pylori values (mean (SEM)) in 11 patients (broken line) before and for 12 months after triple therapy without signs of $\mathbf{H}$ pylori infection at 12 months, expressed as an absorbance index $(A I)$ compared with the absorbance index of the 13 controls (solid line) withou triple therapy. ${ }^{\star} p<0 \cdot 01$.

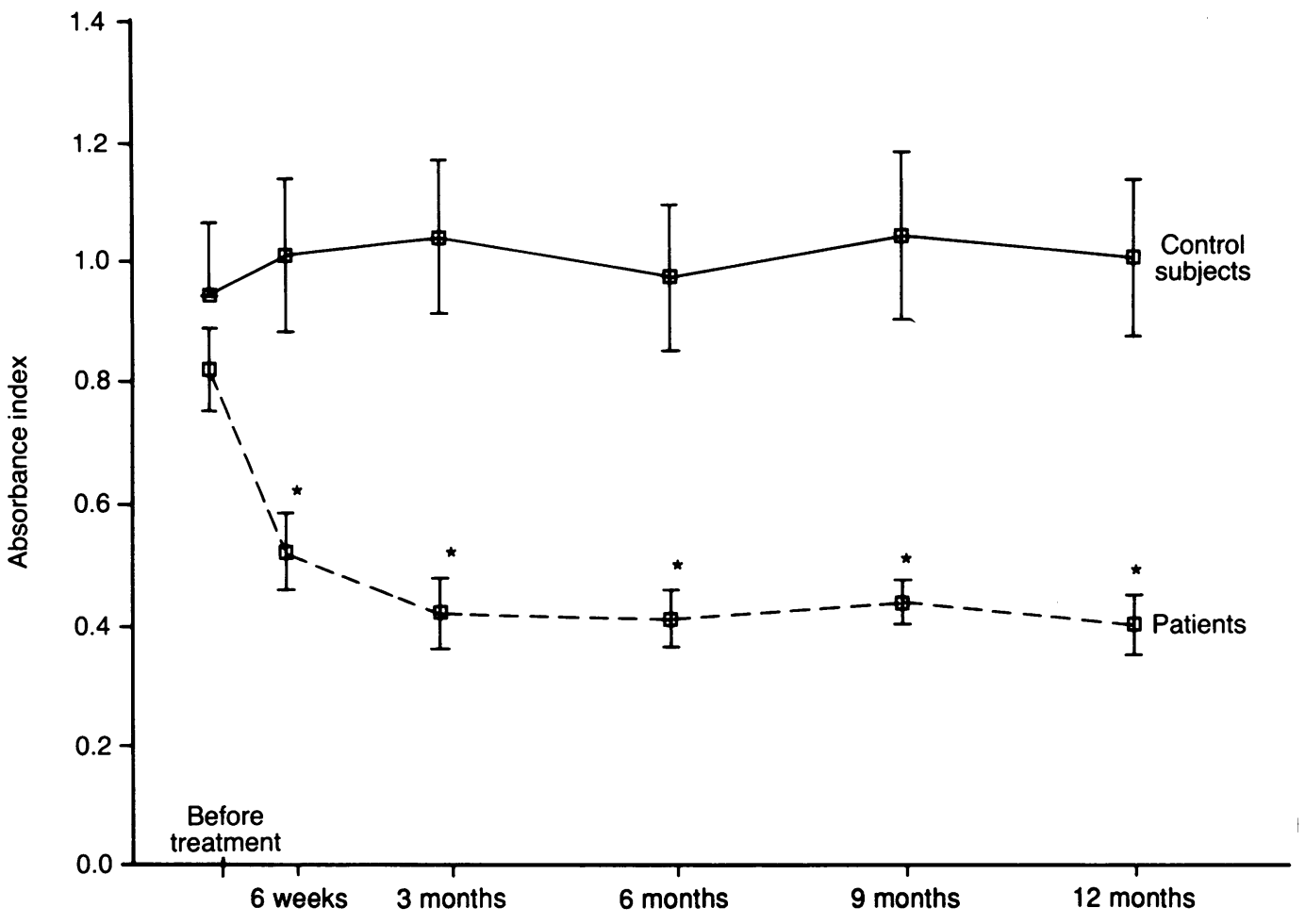

fixed in $10 \%$ buffered formalin, embedded in paraffin and cut into $4 \mu \mathrm{m}$ thick serial sections, which were stained with haematoxylin and eosin. For the present study, infection with $H$ pylori was diagnosed if both active gastritis and bacteria were present.

$\operatorname{IgA}$ and IgG specific antibodies against $H$ pylori were measured by a modified ELISA technique using conjugates labelled with immunoperoxidase specific for human IgA and IgG. For standardisation of the measurement of these antibodies, test conditions were chosen: the mean (SD) values for absorbance of the standard reference serum was taken as $0.5(0 \cdot 1)$ for IgA and $1 \cdot 0(0 \cdot 1)$ for IgG. These values were used to correct the absorbance given by the sera under study.

The absorbance index (AI) was calculated from the mean of two readings of optical density (OD) of serum. The results were expressed as follows:

$$
\mathrm{AI}=\frac{\text { Patient's OD-OD of blank reading }}{\text { Reference OD-OD blank reading }}
$$

An $\mathrm{AI}>0.32$ for anti- $H$ pylori $\mathrm{IgG}$ and an $\mathrm{AI}>0.35$ for anti- $H$ pylori IgA was considered evidence of infection. ${ }^{12}$ The antigen preparation and determination intra- and inter-assay variability of the ELISA technique has been described in detail. ${ }^{12}$

Wilcoxon's rank sum test was used for statistical analysis.

\section{Results}

Thirty subjects (15 in each group) entered the study, but two patients in the triple therapy group failed to meet follow up appointments and were withdrawn. During treatment, side effects of nausea and diarrhoea were frequent but mild, and stopped when treatment ended: no patients dropped out because of these.
$H$ pylori eradication was confirmed by culture and histology in 14 patients three months after beginning treatment.

The ELISA results for specific IgA and IgG anti- $H$ pylori antibodies in the triple therapy and control groups are shown in Figures 1 and 2. Thirteen patients in the control group showed no variation in the mean $\mathrm{AI}$ for $\operatorname{IgA}$ and IgG specific antibodies. Those patients in the triple therapy group without evidence of $H$ pylori infection at 12 months $(n=11)$ showed a significant decrease in the mean AI for both specific IgA and IgG anti- $H$ pylori. After six weeks there was a significant $(\mathrm{p}<0.01)$ decrease in both specific IgA and IgG anti- $H$ pylori antibodies.

Twelve months after the start of triple therapy, the AI for specific IgA was $\leq 0.35$, which is considered the upper limit of normal ${ }^{12}$ in five out of the 11 patients without evidence of $H$ pylori infection at that time. After 12 months, the AI for specific IgG was $\leq 0.32$ (considered the upper limit of normal ${ }^{12}$ ) in only one out of these 11 patients. Nine of the 11 patients are still without evidence of $H$ pylori infection 18 months after starting treatment. In six of these nine the $\mathrm{AI}$ for specific IgA was $\leq 0.35$ and in four the $\mathrm{AI}$ for specific IgG was $\leq 0 \cdot 32$, illustrating a slow but persistent decrease in AI for both immunoglobulins after 12 months of follow up. After treatment, recurrent active $H$ pylori infection and active gastritis were confirmed by culture and histology in three patients $(20 \%)$ in whom worsening symptoms and a rise in specific $\operatorname{IgA}$ anti- $H$ pylori antibodies occurred. In two of these patients a rise in specific IgG anti- $H$ pylori antibody was also found. Individual values of their AI are shown in the Table.

Although it was not the aim of the study, the effect of treatment on symptoms was also monitored. In five patients, symptoms resolved after triple therapy: in the remaining 10, there was no change or only a short term improve- 
Figure 2: Development of specific IgG anti- $\mathrm{H}$ pylori levels in 11 patients before and after triple therapy expressed as an absorbance index $(A I)$ compared with the 19 controls without triple therapy. ${ }^{\star} p<0 \cdot 01$.

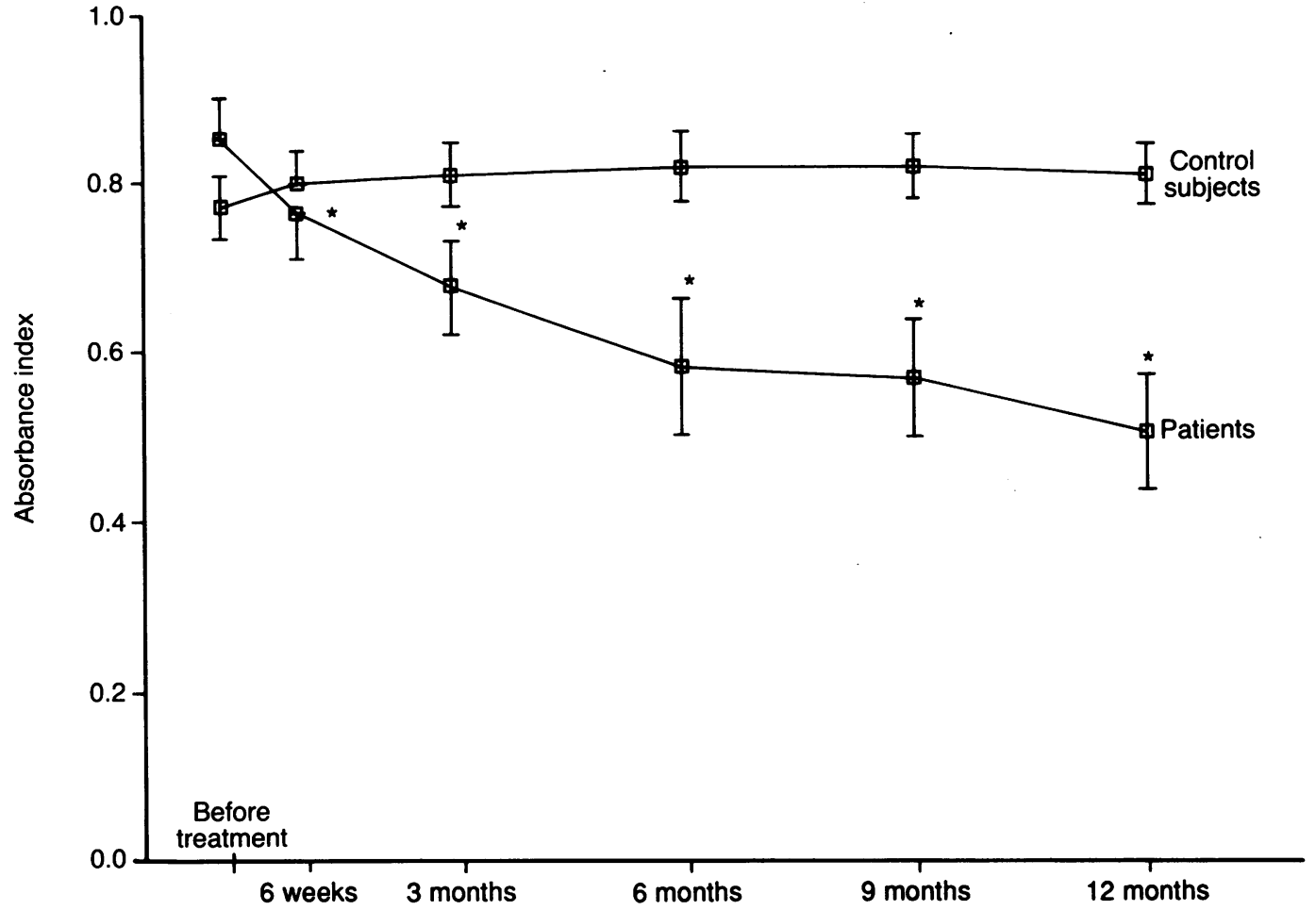

Individual values for specific IgA and IgG anti-H pylori (expressed as absorbance index) in three patients with recurrent active $\mathrm{H}$ pylori infection after treatment with triple therapy

\begin{tabular}{llllllll}
\hline $\begin{array}{l}\text { Patient } \\
\text { No }\end{array}$ & $\begin{array}{l}\text { Before } \\
\text { treatment }\end{array}$ & $\begin{array}{l}\text { At 6 } \\
\text { weeks }\end{array}$ & $\begin{array}{l}\text { At 3 } \\
\text { months }\end{array}$ & $\begin{array}{l}\text { At 6 } \\
\text { months }\end{array}$ & $\begin{array}{l}\text { At 9 } \\
\text { months }\end{array}$ & $\begin{array}{l}\text { At 12 } \\
\text { months }\end{array}$ \\
\hline 1 & IgA & 0.81 & - & 0.46 & 0.33 & $0.52^{\star}$ & - \\
& IgG & 0.81 & - & 0.65 & 0.58 & $0.67^{\star}$ & - \\
2 & IgA & 2.56 & 1.44 & 1.57 & 1.37 & - & $1.48^{\star}$ \\
& IgG & 0.66 & 0.63 & 0.48 & 0.42 & - & $0.27^{\star}$ \\
3 & IgA & 0.86 & 0.60 & 0.62 & 0.53 & $0.86^{\star}$ & - \\
& IgG & 0.63 & 0.59 & 0.57 & 0.50 & $0.78^{\star}$ & - \\
\hline
\end{tabular}

^Infection with $H$ pylori confirmed by culture or histology.

ment. In the three patients whose symptoms recurred and who showed an increase in specific IgA anti- $H$ pylori, infection with $H$ pylori was detected. In six patients, symptoms returned without a concurrent rise in specific IgA or IgG anti- $H$ pylori. In these patients, $H$ pylori infection was not detected by culture or histological examination of gastric biopsy specimens (which showed minimal chronic gastritis only) nor was any abnormality found during endoscopy.

\section{Discussion}

Since the detection of $H$ pylori and its association with chronic active gastritis, ${ }^{1}$ rapid developments have taken place. Not only is $H$ pylori now generally accepted as the cause of type $B$ gastritis but there is also mounting evidence that it is one of the most important factors in duodenal ulcer disease. ${ }^{231516}$ With the development of effective treatment regimens, long term eradication of the bacterium is possible in over $90 \%$ of patients. ${ }^{17}$ Using triple therapy against $H$ pylori, Rauws and Tytgat have recently suggested that a permanent cure for duodenal ulcer disease may be within reach. ${ }^{5}$

Development of non-invasive tests for evaluating the effect of treatment on $H$ pylori in larger numbers of patients has somewhat lagged behind these rapid developments in the field of thera- peutics. There are several excellent tests for the detection of $H$ pylori in untreated patients. ${ }^{12}$ After treatment, however, when the number of bacteria in the mucosa is substantially reduced, the number of false negative test results may increase.

Determination of specific IgA and IgG anti$H$ pylori antibodies by means of an ELISA technique is suitable for screening and follow up in larger patient populations, and several authors have reported a high sensitivity and specificity for diagnosing untreated $H$ pylori infection. ${ }^{12-14}$

There are few well documented studies in which patients have been followed by serological means for longer than six months. In our study, we found that after triple therapy, eradication of the bacterium was reflected in a rapid and significant $(\mathrm{p}<0.01)$ decrease in specific $\operatorname{IgA}$ and IgG anti- $H$ pylori antibody values at six weeks. Specific IgG anti- $H$ pylori antibody values showed a more gradual decrease than those specific for IgA. This rapid decrease in specific IgA anti- $H$ pylori antibodies agrees with the results reported in two short term follow up studies. ${ }^{18} 19$

In our study, recurrence of $H$ pylori infection was indicated by a rise in specific IgA antibody values in three patients and a rise in specific IgG antibody levels in two of them. In all patients with recurrent or persisting complaints, endoscopy and serological examination was performed. Only when recurrent complaints were accompanied by a rise in specific IgA anti$H$ pylori, was infection with $H$ pylori diagnosed. In most patients with no signs of $H$ pylori infection at 12 months, both specific IgA and specific IgG antibody values were lower but had not yet returned to the normal range. At the end of the year, however, five patients had normal IgA anti- $H$ pylori values, and one had a normal IgG value as well.

We conclude that determination of specific 
IgA and IgG antibodies against $H$ pylori is a suitable method of monitoring treatment against $H$ pylori and probably in diagnosing recurrent infection as well. Follow up of longer than 12 months is needed to establish whether a true serological cure of $H$ pylori infection by triple therapy is possible, and whether it will result in normalisation of specific IgA and IgG anti- $H$ pylori antibody values in all patients. Longer follow up is also needed to determine whether low antibody values against $H$ pylori will eventually result in reinfection.

1 Warren JR, Marshall B. Unidentified curved bacilli on gastric epithelium in active chronic gastritis. Lancet 1983; 1 : 1273-5.

2 Marshall BJ, Warren JR. Unidentified curved bacilli in the stomach of patients with

3 Dooley $\mathrm{CP}$, Cohen $\mathrm{H}$, Fitzoibbons PL et al. Prevalence of Helicobacter pylori infection and histologic gastritis in Helicobacter pylon infection and histologic gastritis

4 Marshall BJ, Goodwin CS, Warren JR. Prospective doubleblind trial of duodenal ulcer relapse after eradication of blind trial of duodenal ulcer relapse after e

5 Rauws EAJ, Tytgat GNJ. Cure of duodenal ulcer associated with eradication of Helicobacter pylori. Lancet 1990; 335 1233-5.

6 Goodwin CS. Campylobacter pylori: detection and culture. In Rathbone BJ, Heatley RV. Campylobacter pylori and gastroduodenal disease. Oxford: Blackwell Scientific Publications, 1989: 60-2.
7 Lamouliatte H, Megrand F, De Mascarel A, Roux D, Quinton A. Campylobacter pyloridis and epigastric pain: endoscopic histological and bacteriological correlations. Gastroenterol Clin Biol 1987; 11: 212-6.

8 Madan E, Kemp J, Westblom U, Subik M, Sexton S, Cook J Evaluation of staining methods for identifying Campylobacter pylori. Am f Clin Pathol 1988; 90: 450-3.

9 McNulty CAM, Wise R. Rapid diagnosis of Campylobacterassociated gastritis. Lancet 1985 ; i: $1443-4$.

10 Graham DY, Klein PD, Evans DI, et al. Campylobacter pylor detected non-invasively by the ${ }^{3} \mathrm{C}$-urea breath test. Lancet 1987; i: 1174-7.

11 Rauws EAJ, Royen EAV, Langenberg W, Woensel JV, Vri AA, Tytgat GNJ. ${ }^{14} \mathrm{C}$-urea breath test in $C$.pylori gastritis. Aut 1989; 30: 798-803.

12 Peña AS, Endtz HPh, Offerhaus GJA, et al. Value of serology (ELISA and immunoblotting) for the diagnosis of Campylobacter pylori infection. Digestion 1989; 44: 131-4

13 Perez-Perez AI, Dwarkin BM, Chodos JE, Blaser MJ Campylobacter pylori antibodies in humans. Ann Intern Med 1988; 109: 11-7.

14 Evans DJ, Evans DG, Graham DY, Klein PD. A sensitive and specific serologic test for detection of Campylobacter pylori infection. Gastroenterology 1989; 96: 1004-8

15 Coghlan JG, Humphreys H, Dooley C, et al. Campylobacter pylori and recurrence of duodenal ulcer - a 12 months followup study. Lancet 1987; i: 1109-11.

16 Goodwin CS. Duodenal ulcer, Campylobacter pylori, and the 'leaking roof concept. Lancet 1988; ii: 1467-9.

17 Borody TJ, Cole P, Noonan S, et al. Recurrence of duodenal ulcer and Campylobacter pylori infection after eradication. ulcer and Campylobacter pylori

18 Vaira D, Holton J, Cairns SR, et al. Antibody titres to Campylobacter pylori after treatment for gastritis. BMF 1988; 297: 397.

19 Gobert B, Bene MC, De Korwin JD, Faure G. Isotype evolution in the follow-up study of patients with Campylobacter pylori associated gastritis. Gastroenterol Clin Biol 1989; 13: $880-3$ 